\title{
Characteristics of Individuals Admitted to the Intensive Care Unit for Asthma
}

Jacqueline Simatovic ${ }^{1}$, Jingqin Zhu'1,2, Chenwei Gao ${ }^{1,2}$, Laura Feldman ${ }^{1,3}$, Devon Williams ${ }^{1}$, Andrea S. Gershon ${ }^{1,2,4,5}$, Diane Lougheed M ${ }^{6,7}$, Chris Licskai ${ }^{8}$, Sharon Dell ${ }^{1,2}$ and Teresa To $^{1,2,3,4 *}$

${ }^{1}$ Child Health Evaluative Sciences, The Hospital for Sick Children, Toronto, Canada

${ }^{2}$ Institute for Clinical Evaluative Sciences, Toronto, Canada

${ }^{3}$ Dalla Lana School of Public Health, Canada

${ }^{4}$ Institute of Health Policy, Management and Evaluation, University of Toronto, Toronto, Canada

${ }^{5}$ Sunnybrook Health Sciences Centre, Toronto, Canada

${ }^{6}$ Clinical Research Centre, Kingston General Hospital, Kingston, Canada

${ }^{7}$ Department of Medicine, Queen's University, Kingston, Canada

${ }^{8}$ Schulich School of Medicine \& Dentistry, Western University, London

\begin{abstract}
Introduction: While asthma mortality and hospitalizations have decreased substantially over the past two decades, asthma prevalence has increased, and a number of individuals still present with severe asthma. As intensive care unit (ICU) admissions can be used as a marker for severe asthma, there is utility in continuing to monitor ICU trends and the descriptive profile of individuals admitted to the ICU.

Methods: Health administrative population data from Ontario, Canada, were used to describe ICU admission trends by age group from 2003 to 2012 and the characteristics of those admitted to ICU. Descriptive analyses were performed for both hospitalized patients and ICU patients for age, sex, rurality, neighborhood income quintile and comorbidities.

Results: ICU admission rates per 100,000 asthma population decreased steadily over time (56.4 in 2003; 31.1 in 2012), but increased in the $0-4$ (73.9 in 2003; 85.9 in 2012) and 5-14 (11.1 in 2003; 18.8 in 2012) age groups. Compared to individuals who were hospitalized only, a greater proportion of older individuals, females, children with other respiratory conditions, and adults with acute myocardial infarction were admitted to the ICU.

Conclusions: While the overall rate of ICU admissions has decreased over time, it has increased in children aged $0-14$. This study identified high risk groups who are more likely to be admitted to the ICU. These individuals may benefit from targeted interventions to improve asthma control and reduce their future risk of admission to the ICU.
\end{abstract}

Keywords: ICU; Health administrative data; Morbidity; Respiratory; Population data

\section{Introduction}

While asthma mortality and hospitalizations have decreased substantially over the past two decades, asthma prevalence has increased, and a number of individuals still present with severe asthma [1,2]. Those with severe asthma are more likely to have life-threatening asthma exacerbations that can lead to death [2]. Eisner et al. identified admissions to the Intensive Care Unit (ICU) as a feasible and valid way to identify adults with severe asthma [3]. Individuals admitted to the ICU are more likely to have greater objective asthma severity scores, lower quality of life, higher self-perceived asthma severity, and are at greater risk of dying from asthma [3-5]. Risk factors for asthma ICU admission include an earlier hospitalization, being of the female gender, lacking health insurance, and presence of comorbidities [6-8]. Pendergraft et al. found that the most common comorbidities within those admitted to the ICU for asthma were pneumonia, hypertension, diabetes mellitus, acute respiratory tract infection, and heart failure [8].

National and international guidelines increasingly emphasize the importance of achieving asthma control and reducing the risk of future exacerbations [1,9]. It is important to continue to monitor asthma ICU rates over time to ensure that they continue to decline. Further, a better understanding of individuals admitted to the ICU for asthma is clinically useful to identify patients who are at higher risk for near-fatal exacerbations and to identify groups to target with interventions aimed at improving awareness and control of asthma symptoms. Thus, the objective of this study was to use population data to describe the trend of ICU admissions by age group over time and the characteristics of those admitted to the ICU.

\section{Methods}

Population data from Ontario, Canada, were used for this study.
Ontario has a universal, single-payer health-care system that covers all physician and hospital services. Data were used from the following health administrative databases: 1) Ontario Health Insurance Plan Database - contains fee-for-service billings for physician services and emergency department visits; 2) Canadian Institute for Health Information (CIHI) Discharge Abstract Database - records primary and secondary diagnoses for hospital and ICU admissions; 3) Ontario Registered Persons Database includes information on sex, birth date and residence postal code. These databases were linked at the individual level using an encrypted unique health card number given to all Ontario residents. Individuals with asthma were identified as those who, from 1991 to 2012, had at least two asthma outpatient claims in two consecutive years or one hospitalization for asthma. This administrative data definition for asthma has been validated in both children and adults [10,11]. International classification of disease (ICD-9 and ICD-10) codes used for asthma, asthma-related conditions, chronic obstructive pulmonary disease (COPD), and other respiratory conditions are listed in the Appendix.

Hospitalizations for asthma and subsequent admissions to the ICU between 2003 and 2012 were extracted from the CIHI database.

*Corresponding author: Dr. Teresa To, The Hospital for Sick Children Child Health Evaluative Sciences 555, University Avenue, Toronto Ontario, M5G 1X8, Canada, Tel: 416-813-8498; Fax: 416-813-5979, E-mail: teresa.to@sickkids.ca

Received October 25, 2014; Accepted April 10, 2015; Published April 14, 2015

Citation: Simatovic J, Zhu J, Gao C, Feldman L, Williams D, et al. (2015) Characteristics of Individuals Admitted to the Intensive Care Unit for Asthma. Pulm Respir Med 5: 256. doi:10.4172/2161-105X.1000256

Copyright: @ 2015 Simatovic J, et al. This is an open-access article distributed under the terms of the Creative Commons Attribution License, which permits unrestricted use, distribution, and reproduction in any medium, provided the original author and source are credited. 
Hospital admissions with asthma listed only as a secondary diagnosis type were excluded from the analysis. Individuals with at least one ICU visit were identified as ICU patients, using the first ICU discharge date as the index date. First hospital discharge dates were used as the index dates for hospitalized individuals without ICU admissions. Demographic information was extracted from the Ontario Registered Persons Database. Postal code was used to determine if a patient resided in a rural or urban setting. Rurality was defined as living in a municipality with fewer than 10,000 people.

Asthma ICU admission rates were calculated among age groups from 2003 to 2012. A 2-way ANOVA was used to determine if ICU rates differed between age groups each year and within age groups across all years. Descriptive analyses were performed for both hospitalized patients and ICU patients at index date for age in years, sex, rurality, neighborhood income quintile, death, and comorbidities. Standardized difference scores $[12,13]$ were calculated for each of the patient characteristics. Standardized difference scores are independent of sample size, and measure the effect size between two groups. Using this test, differences between the hospitalized only and ICU group were considered statistically significant if the absolute value was greater than 0.20 (small effect size) $[12,13]$.

\section{Results}

Asthma ICU admission rates per 100,000 asthma population showed that, overall, the rate of patients admitted to the ICU has decreased over time (from 56.4 in 2003 to 31.1 in 2012; Figure 1). The rate of asthma ICU admissions per 100,000 asthma population decreased substantially in those aged 60+ (from 132.9 in 2003 to 50.8 in 2012), but increased in the 0-4 age group (from 73.9 in 2003 to 85.9 in 2012) and the 5-14 age group (from 11.1 in 2003 to 18.8 in 2012).

Table 1 contains the descriptive profile of asthma patients who were ever hospitalized or admitted to the ICU for asthma from 2003 to 2012. Compared to individuals who were hospitalized only, a greater proportion of individuals in the 30-39, 40-49, 50-59, 60-69, and 70+ age groups were admitted to the ICU (Table 1). There was also a greater proportion of females in the ICU group compared to the hospitalized only group (Table 1). No statistically significant differences were found between the two groups for rurality and income quintile (Table 1). While the two groups did not have a different proportion of comorbidities as a whole, the ICU group had a greater proportion of children with other respiratory conditions, and adults with acute myocardial infarction (Table 1). The ICU only group had a much greater proportion of individuals who died during the study period (Table 1). Of the 5335 individuals included in Table 1 who were admitted to the ICU, 4834 were admitted only once from 2003 to 2012, 337 were admitted twice, 92 were admitted three times, 27 were admitted four times, 15 were admitted five times, and 30 were admitted more than five times (mean $=1.17 \pm 0.9 ; \min =1 ; \max =41$ ).

\section{Discussion}

In summary, the overall rate of ICU admissions for asthma has decreased over time, except for in children 0-14 years of age. The increasing trend in asthma ICU admission observed in children is alarming and warrants further investigation. Compared to individuals who were admitted to the hospital only, a greater proportion of older individuals, females, children with other respiratory conditions, and adults with acute myocardial infarction were admitted to the ICU.

Our findings parallel those of previous studies. Gibbison et al. found that of those admitted to the critical care unit for asthma, $67.5 \%$ were female,

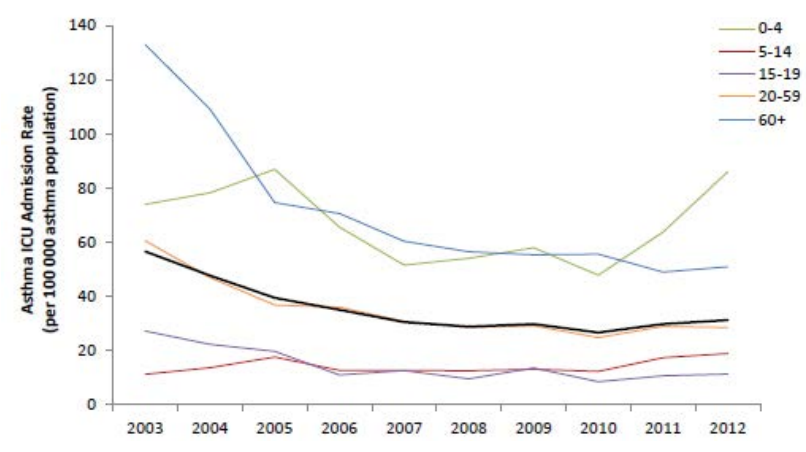

Figure 1: Asthma ICU admission rate per 100,000 asthma population by age, from 2003 to 2012 .

and $32.5 \%$ were male [14]. This difference in gender may be due to a gender bias. Women may delay seeking care resulting in delayed diagnosis and treatment of asthma, increasing the likelihood that the asthma symptoms would escalate and result in a severe asthma episode and admission to the ICU [15]. Other groups of individuals that were disproportionally distributed were children with other respiratory conditions and adults with acute myocardial infarction. These individuals may have more complicated disease profiles, increasing their likelihood of being admitted to the ICU. It may also be the case that they are not receiving optimal care of their chronic conditions, increasing the likelihood that their symptoms become severe enough to warrant an admission to the ICU.

Some limitations of this study should be noted. First, while the asthma case definition used in this study has been previously validated with chart abstraction studies [10,11], the health administrative data definition of asthma may be subject to potential misclassification when compared to clinical evaluation by a physician. Second, not all parameters relevant to ICU risk profile were available using administrative data (e.g., compliance to treatment, recently used drugs and/or doses). Future research would do well to measure these difficult-to-collect variables.

Since admission to the ICU is a marker of severe asthma, there is utility in knowing more about ICU trends over time and the population who are admitted to the ICU. This study identified females, older adults, children with other respiratory conditions, and adults with acute myocardial infarction as high risk groups who are more likely to be admitted to the ICU. These individuals may benefit from targeted interventions to improve asthma control and reduce their future risk of admission to the ICU.

\section{Declaration of Interest}

The authors report no conflicts of interest. The authors alone are responsible for the content and writing of the paper.

\section{Author Contributorship}

All of the authors were involved in the study concept and design. Jacqueline Simatovic and Teresa To were responsible for interpretation of the data, drafting and revising the manuscript. Jingqin Zhu and Chenwei Gao were responsible for data extraction and analysis. All authors assisted with revising the manuscript. All authors have approved the manuscript as submitted and take full responsibility for the manuscript.

\section{Funding}

The study was supported by the Ontario Ministry of Health and Long-Term Care. Data were provided by the Institute for Clinical Evaluative Sciences. The opinions, results and conclusions reported in this paper are those of the authors and are independent from the funding sources. No endorsement by the Government of Ontario is intended or should be inferred. 
Citation: Simatovic J, Zhu J, Gao C, Feldman L, Williams D, et al. (2015) Characteristics of Individuals Admitted to the Intensive Care Unit for Asthma. J Pulm Respir Med 5: 256. doi:10.4172/2161-105X.1000256

Page 3 of 4

\begin{tabular}{|c|c|c|c|}
\hline & Hospitalization Only ( $n=55,815)$ & ICU $(n=5,335)$ & Standardized Difference $†$ \\
\hline \multicolumn{4}{|l|}{ Age, in years } \\
\hline $0-4$ & $23,899(42.8 \%)$ & $614(11.5 \%)$ & 0.65 \\
\hline $5-9$ & $6,382(11.4 \%)$ & $261(4.9 \%)$ & 0.21 \\
\hline $10-14$ & $2,243(4.0 \%)$ & $189(3.5 \%)$ & 0.02 \\
\hline $15-19$ & $1,293(2.3 \%)$ & $217(4.1 \%)$ & 0.11 \\
\hline $20-29$ & $2,406(4.3 \%)$ & $408(7.6 \%)$ & 0.16 \\
\hline $30-39$ & $2,703(4.8 \%)$ & $552(10.3 \%)$ & 0.25 \\
\hline $40-49$ & $3,505(6.3 \%)$ & $665(12.5 \%)$ & 0.25 \\
\hline $50-59$ & $3,607(6.5 \%)$ & $623(11.7 \%)$ & 0.21 \\
\hline $60-69$ & $3,048(5.5 \%)$ & $630(11.8 \%)$ & 0.27 \\
\hline $70+$ & $6,729(12.1 \%)$ & $1,176(22.0 \%)$ & 0.30 \\
\hline \multicolumn{4}{|l|}{ Sex } \\
\hline Female & $28,078(50.3 \%)$ & $3,272(61.3 \%)$ & 0.22 \\
\hline Male & $27,737(49.7 \%)$ & $2,063(38.7 \%)$ & \\
\hline \multicolumn{4}{|l|}{ Rurality } \\
\hline Rural & $6,530(11.7 \%)$ & $763(14.3 \%)$ & 0.08 \\
\hline Urban & $49,258(88.3 \%)$ & $4,569(85.7 \%)$ & \\
\hline \multicolumn{4}{|l|}{ Income Quintile } \\
\hline 1 (lowest income) & $13,918(25.1 \%)$ & $1,432(27.0 \%)$ & 0.04 \\
\hline 2 & $11,912(21.5 \%)$ & $1,185(22.4 \%)$ & 0.02 \\
\hline 3 & $11,125(20.1 \%)$ & $1,026(19.4 \%)$ & 0.02 \\
\hline 4 & $10,093(18.2 \%)$ & $942(17.8 \%)$ & 0.01 \\
\hline 5 (highest income) & $8,438(15.2 \%)$ & $717(13.5 \%)$ & 0.05 \\
\hline \multicolumn{4}{|l|}{ Comorbidities } \\
\hline Children $(\leq 19)$ & $(n=33,817)$ & $(n=1,281)$ & \\
\hline Asthma-related conditions & $33,190(98.1 \%)$ & $1,253(97.8 \%)$ & 0.02 \\
\hline Other respiratory conditions & $3,596(10.6 \%)$ & $334(26.1 \%)$ & 0.49 \\
\hline Diabetes & $90(0.3 \%)$ & $14(1.1 \%)$ & 0.15 \\
\hline Any of the above comorbidities & $33,194(98.2 \%)$ & $1,253(97.8 \%)$ & 0.03 \\
\hline Adults $(\geq 20)$ & $(n=21,998)$ & $(n=4,054)$ & \\
\hline Asthma-related conditions & $21,766(98.9 \%)$ & $3,998(98.6 \%)$ & 0.03 \\
\hline Other respiratory conditions & $11,626(52.9 \%)$ & $2,142(52.8 \%)$ & 0.00 \\
\hline Diabetes & $5,408(24.6 \%)$ & $1,177(29.0 \%)$ & 0.10 \\
\hline Lung cancer & $163(0.7 \%)$ & $37(0.9 \%)$ & 0.02 \\
\hline Cancer (other than lung) & $1,889(8.6 \%)$ & $394(9.7 \%)$ & 0.04 \\
\hline COPD & $9,699(44.1 \%)$ & $1,910(47.1 \%)$ & 0.06 \\
\hline Hypertension & $10,829(49.2 \%)$ & $2,089(51.5 \%)$ & 0.05 \\
\hline $\mathrm{CHF}$ & $3,687(16.8 \%)$ & $944(23.3 \%)$ & 0.17 \\
\hline AMI & $953(4.3 \%)$ & $426(10.5 \%)$ & 0.28 \\
\hline Stroke & $2,649(12.0 \%)$ & $485(12.0 \%)$ & 0.00 \\
\hline IHD & $6,969(31.7 \%)$ & $1,448(35.7 \%)$ & 0.09 \\
\hline Angina & $4,933(22.4 \%)$ & $1,063(26.2 \%)$ & 0.09 \\
\hline Any of the above comorbidities & $21,881(99.5 \%)$ & $4,034(99.5 \%)$ & 0.01 \\
\hline \multicolumn{4}{|l|}{ Mechanical Ventilation } \\
\hline No & $72(0.1 \%)$ & $1,395(26.1 \%)$ & 1.94 \\
\hline Yes & $55,743(99.9 \%)$ & $3,940(73.9 \%)$ & \\
\hline \multicolumn{4}{|l|}{ Death } \\
\hline Yes & $4,545(8.1 \%)$ & $1,149(21.5 \%)$ & 0.46 \\
\hline No & $51,270(91.9 \%)$ & $4,186(78.5 \%)$ & \\
\hline
\end{tabular}

Note: $†$ Standardized difference=difference in means or proportions divided by standard error; imbalance defined as absolute value greater than 0.20 (small effect size). $\mathrm{ICU}=$ intensive care unit; $\mathrm{COPD}=$ chronic obstructive pulmonary disease; $\mathrm{CHF}=$ congestive heart failure; $\mathrm{AMI}=$ acute myocardial infarction; $\mathrm{IHD}=\mathrm{ischemic}$ heart disease; This table includes unique persons at time of their first ICU visit, or first hospitalization for asthma (if they did not have an ICU visit). Index date is the discharge date of the first asthma hospitalization or the first ICU during the study period (April 1, 2003 - March 31, 2013); Age group, rurality, income quintile were identified at the index date; Mechanical ventilation and death were identified at the end of the study. All comorbidities were identified using information before the index date. Percentages were adjusted for missing data.

Table 1: Descriptive profile of asthma prevalence population ( $n=1,946,544)$ hospitalized at least once, from 2003 to 2012. 
Citation: Simatovic J, Zhu J, Gao C, Feldman L, Williams D, et al. (2015) Characteristics of Individuals Admitted to the Intensive Care Unit for Asthma. J Pulm Respir Med 5: 256. doi:10.4172/2161-105X.1000256

\section{References}

1. Polosa R, Bellinvia S, Caruso M, Emma R, Alamo A, et al. (2014) Weekly lowdose methotrexate for reduction of Global Initiative for Asthma Step 5 treatment in severe refractory asthma: study protocol for a randomized controlled trial. Trials 15: 492

2. Rebuck AS (2013) The global decline in asthma death rates: can we relax now? Asia Pac Allergy 3: 200-203.

3. Eisner MD, Boland M, Tolstykh I, Mendoza G, Iribarren C (2005) Intensive care unit admission for asthma: a marker for severe disease. J Asthma 42: 315-323.

4. Alvarez GG, Schulzer M, Jung D, Fitzgerald JM (2005) A systematic review of risk factors associated with near-fatal and fatal asthma. Can Respir J 12: 265-270.

5. Belessis Y, Dixon S, Thomsen A, Duffy B, Rawlinson W, et al. (2004) Risk factors for an intensive care unit admission in children with asthma. Pediatr Pulmonol 37: 201-209.

6. van den Bosch GE, Merkus PJ, Buysse CM, Boehmer AL, Vaessen-Verberne $A A$, et al. (2012) Risk factors for pediatric intensive care admission in children with acute asthma. Respir Care 57: 1391-1397.

7. Keller K, Sran S, Laszlo D, Georgitis JW (1994) Acute asthma management in children: factors identifying patients at risk for intensive care unit treatment. $J$ Asthma 31: 393-400.
8. Pendergraft TB, Stanford RH, Beasley R, Stempel DA, Roberts C, et al. (2004) Rates and characteristics of intensive care unit admissions and intubations among asthma-related hospitalizations. Ann Allergy Asthma Immunol 93: 29-35.

9. Lougheed MD, Lemiere C, Ducharme FM, Licskai C, Dell SD, et al. (2012) Canadian Thoracic Society 2012 guideline update: Diagnosis and management of asthma in preschoolers, children and adults. Can Respir J 19: 38.

10. To T, Dell S, Dick PT, Cicutto L, Harris JK, et al. (2006) Case verification of children with asthma in Ontario. Pediatr Allergy Immunol 17: 69-76.

11. Gershon AS, Wang C, Guan J, Vasilevska-Ristovska J, Cicutto L, et al. (2009) Identifying patients with physician-diagnosed asthma in health administrative databases. Can Respir J 16: 183-188.

12. Flury BK, Riedwyl H (1986) Standard distance in univariate and multivariate analysis. The American Statistician 40: 249-251.

13. Austin PC (2009) The relative ability of different propensity score methods to balance measured covariates between treated and untreated subjects in observational studies. Med Decis Making 29: 661-677.

14. Gibbison B, Griggs K, Mukherjee M, Sheikh A (2013) Ten years of asthma admissions to adult critical care units in England and Wales. BMJ Open 3: e003420.

15. Wright AL, Stern DA, Kauffmann F, Martinez FD (2006) Factors influencing gender differences in the diagnosis and treatment of asthma in childhood: the Tucson Children's Respiratory Study. Pediatr Pulmonol 41: 318-325. 